\title{
ESTUDIO DEL NEMATODO CONTRACAECUM OSCULATUM ENCONTRADO EN LOBOS MARINOS DE DOS PELOS EN LA ZONA DE ILO - PERU
}

\author{
Víctor Gutiérrez Espejo', Quiterio Valencia \\ Mécola ${ }^{2}$, LeonardoSheron Ramírez $^{3}$, Manuel \\ Tantaleán ${ }^{3}$
}

\begin{abstract}
RESUMEN
De tres lobos finos de dos pelos, Arctocephalus australis, capturados en las playas marinas de Punta de Coles (Ilo), ubicadas entre las coordenadas 17'42'S71022'50 (Sur Deste) entre los meses de febrero y octubre de 1992 en Tacna-Perú, fueron obtenidas las muestras a través de pruebas, según metodología para parásitos de peces especificamente Nemátodos y Tinción con Carmin, enconträndose un porcentaje significativo de Contracaecum osculatum, en cada uno de los lobos finos de dos pelos.
\end{abstract}

\section{INTRODUCCION}

Los lobos integrantes del ecosistema marino representan un recurso natural renovable, que es de gran importancia en la comercialización de sus pieles y ejemplares vivos.

La ciencia reconoce la existencia del Octaria flavercens, "Lobo marino chusco, o de un pelo" y el Arctocephalus australis "Lobo fino o de dos pelos", siendo éste un mamífero pequeño y fino por su piel.

Este espécimen se halla ampliamente distribuidas portodoelcontinente. Es así que enelPerú se le puede observara todo lo largo de nuestro litoral, desde la frontera con Chile hasta la Isla Lobos de Tierra, bien al norte.

En el presente informe, se comunica la presencia de helmintos, parásitos hallados en tres ejemplares de Arctocephalus australis, capturados en playas marinas del Puerto de llo: Punta de Coles, que se encuentra entre las coordenadas $17^{\circ} 42^{\prime} 5$ y $71^{\circ} 22^{\prime} \mathrm{W}$ (Sur Oeste), entre febrero yoctubre de 1992 (tabla 1). Todoslos lobos examinados eran de sexo masculino (machos), y su longitud total fluctuaba entre $1 / .84 \mathrm{mts}$. y $2.43 \mathrm{mts}$. y envergadura era entre $1.28 \mathrm{mts}$. y $2 \mathrm{mts}$.

El contenido estomacal e intestinal fue colectado y fijado con formol $10 \%$, o etanol $70 \%$, los helmintos parásitos fueron procesados en el laboratorio de microbiología y parasitología de la Universidad Nacional

1. Microbiólogo

2. Doctor en pesquería

3. Ingeniero pesquero
Jorge Basadre Grohmann de Tacna-Perú yenel Instituto de Enfermedades Tropicales de la Universidad Mayor de San Marcos de Lima - Perú, donde se procedió a aclarar y colorear con carmín nemátodos, con la finalidad de identificarlos taxonómicamente.

La finalidad del presente trabajo es determinar indirectamente la contaminación de los lobos marinos finos por la ingesta de peces, infectados con Contracaecum osculatum, y el posible peligro para la salud pública, al consumir la carne semicocida o cruda del lobo marino fino.

\section{MATERIAL Y METODOS}

De las tres muestras obtenidas del sistema digestivo del lobo marino fino, se examinaron independientemente cada parte: esófago, estómago, intestino delgado y el intestino grueso respectivamente.

\section{MUESTRAS PARA EL LABORATORIO}

Se obtuvieron tres muestras del contenido estomacal del lobo fino Arctcephalus australis.

\section{MATERIAL DE LABORATORIO}

Pipetas calibradas de $1 \mathrm{ml}, 10 \mathrm{ml}$, placas petri, bisturí, pinzas, estilete, pinceles, lámina porta-objeto, laminillas cubre objeto, microscopio, stereoscopios, estufa.

\section{REACTIVOS}

Solución salina fisiológica, agua potable, batería de alcoholes: $30 \%, 50 \%, 70 \%, 80 \%, 90 \%$, formol $10 \%$, alcohol ácido 1-2\%, alcohol ácido fuerte $3 \%$, acetona, 
metanel, xilol, creosota, salicilato, metilo o terfinol, bálsamo de Canadá.

\section{METODOLOGIA}

Obtención de la muestra: Para su colección se procedió de la siguiente forma:

a) Se realizó un corte transversal del tubo digestivo, para separar el esófago, estómago, intestino delgado, intestino grueso, los cuales se colocan aisladamente en placas petri o bandejas con S.S.F.

b) Exponer totalmente la cavidad de cada porción, mediante un corte longitudinal.

c) Desprender cuidadosamente los parásitos que se encuentran adheridos en la pared intestinal, agregando S.S.F. tibia o mediante estiletes.

d) Los helmintos pequeños que se encuentran adheridos a la pared intestinal, deben obtenerse raspando con un bisturi la mucosa, la cual debe ser colocada en una placa petri con $\mathrm{G}$. Salina.

e) Colocar los parásitos en una caja petri con S. Salina limpia, donde serán lavados mediante movimientos suaves con un estilete, evitando romper los órganos adhesivos.

\section{COLORACION CON CARMIN}

a) Lavado, b) Deshidratación, c) Tinción, d) Decolorar, e) Deshidratación,f) Aclaramiento, g) Montaje,h) Secado.

\section{RESULTADOS}

La carga parasitaria colectada alcanzó 140 nemátodos adultos, además de producción de huevos de las hembras.

\begin{tabular}{|c|c|c|c|c|}
\hline \multirow{2}{*}{$\begin{array}{c}\text { NÚM. } \\
\text { DELOBOS }\end{array}$} & \multirow{2}{*}{ TAMAÑO } & \multicolumn{2}{|c|}{ ESPECIE \% } & \multirow{2}{*}{ HABITAT } \\
\cline { 3 - 4 } & & CONTRACAECUM & OSCULATUM & \\
\hline 1 & $2.43 \mathrm{mts}$. & 60 & 100 & Estómago \\
1 & $1.90 \mathrm{mts}$. & 29 & 100 & Estómago \\
1 & $1.84 \mathrm{mts}$ & 51 & 100 & Estómago \\
\hline
\end{tabular}

El porcentaje de identificación del nemátodo Contracaecum osculatum, teniendo en cuenta partes

\section{BIBLIOGRAFIA}

W. Hisamoto, T. Llorena P. 1980. Anisakis gástrica en Chile Rev. Med. Chile 108:825 - 827

George - Nacimiento - Carbajal Y. Nuevos registros de nemátodos en la Fauna Marina Chilena. Bol. Chile Parasit. 25: 15 - 18.

Delley, M. D. 1980. Diagnostic key to the Parasites of some Marine mammains N.G.S.C.technical document. 295: $37 \mathrm{pp}$. del sistema digestivo, en lobos marinos finos de Punta de Coles, llo - Perú, se aprecia en el cuadro anterior.

\section{DISCUSION}

Es importante reconocer que sólo a partir de los trabajos de Daley y Brownell, en 1972, se empezaron a identificar a los géneros de los parásitos; sin embargo, en 1980 Daley publica listas adicionales que se refieren sólo a parásitos de mamíferos marinos de Norte - América.

Una de las razones de las investigaciones parasitológicas en mamíferos marinos, es su implicancia en salud pública, debido a que posiblemente en estado larvario, estos parásitos habiten en huéspedes intermediarios que en su gran mayoría son peces y normalmente alcanzan el estado adulto cuando los lobos consumen peces.

El ser humano al consumir la carne de Arctocephalus australis, crudo, o semicocido, puede contraer enfermedades de origen marino.

Esto lo ha demostrado Williams y Jones (1976) con relación al nemátodo Contracacecum sp, que es peligroso para la salud pública.

Los reportes encontrados por Williams corroboran con loaislado pornosotros en llo-Perú, los nemátodos de Contracacecum sp han sido hallados en lobos marinos en Talcahuano, porGeorge NascimentoyCarbajal en 1980 en Chile.

\section{CONCLUSIONES}

- Los nemátodos de Contracacecum osculatum se encuentran en el estómago del lobo marino fino de dos pelos.

- La especie parasitaria puede serpeligrosa para la salud pública, al ser consumida la carne del Arctocephalus australis, semicocida, o cruda.

- Se debe consumirla carne del lobo fino cocida, para evitar cuadros patológicos, como lainfestación del ser humano.

- Este hallazgo indica que el lobo fino sufre contaminación por la ingesta de peces, y representa un peligro para la salud del ser humano.

Pedro E. Cdttan, José L. Yañez y Daniel Torres. Helmintos parásitos del lobo fino Arcttocephalus philippie bold. Chile parasit.

Davey J.T.A. Revisión of the Genus. Anisakis Du jardin (nemátoda: escaridata). J. Helmintohol. 45: 51 . 72. 1971. 